\title{
New Semicrystalline Block Copolymers of Poly(arylene ether sulfone)s and Poly(1,4-cyclohexylenedimethylene terephthalate)
}

Zhengmian Chang, Gregory B. Fahs, Bin Zhang, Hans E. Edling, E. Bruce Orler, Robert B. Moore, and S. Richard Turner*

Department of Chemistry, Macromolecules and Interfaces Institute (MII), Virginia Tech, Blacksburg, Virginia, 24061, USA

${ }^{*}$ Corresponding author. Tel.: +1 540231 4552; fax: +1 540231 3971. E-mail address: srturner@vt.edu (S. R. Turner).

\section{Abstract:}

Multiblock copolymers of poly(arylene ether sulfones) (PAESs) and poly $(1,4-$ cyclohexylenedimethylene terephthalate) (PCT) were synthesized via melt-phase polymerization. PAES oligomers $\left(M_{n}=2000 \mathrm{~g} / \mathrm{mol}\right)$ were synthesized with hydroxyethoxyl end groups, and then reacted with dimethyl terephthalate (DMT) and 1,4-cyclohexanedimethanol (CHDM) to obtain segmented copolymers with the goal of introducing semi-crystallinity into the PAES segmented block copolymers. Two CHDM (all trans and cis/trans $=30 / 70$ ) were used for comparison. Weight percentages of PCT segments varied from $20 \mathrm{wt} \%$ to 80 wt\%. According to the results measured by DSC, DMA and WAXS, the copolymers crystallized when the content of PCT segment was above 50 wt\%, and the crystallinity of the copolymers exhibited a proportional dependence on the weight percentage of PCT segments. Segmented copolymers with trans- 
CHDM as the polyester segment exhibited a higher level of crystallinity than the 30/70 CHDM mixture.

\section{Introduction}

Poly(arylene ether sulfones) (PAESs) are high performance polymers with high glass transition temperatures $\left(T_{g}\right)$, thermal and hydrolytic stabilities, and excellent mechanical properties [1-3]. With these attractive features, PAESs have found extensive applications in the field of engineering plastics, membrane materials and biomaterials. However, due to the different bond angles of the aromatic ether $\left(121^{\circ}\right)$ and the sulfonyl $\left(106^{\circ}\right)$ groups, PAES chains cannot pack effectively, which prevents crystallization [4]. Thus, when compared to semicrystalline polymers, PAESs exhibit relatively low chemical resistance and dimensional stability at elevated temperature, etc. Efforts have been made to introduce crystallinity into the PAES systems, and expand applications by chemical structure modification $[5,6]$.

Crystallinity can be imparted into amorphous PAESs by chemical structure modification. Kwiatkowski et al. prepared poly(ether ketone ketone)/poly(ether sulfone) (PEKK/PES) block copolymers via nucleophilic polycondensation. The copolymers were semi-crystalline when PEKK composition exceeded $65 \mathrm{wt} \%$, and had $\mathrm{T}_{\mathrm{m}} \mathrm{s}$ above $300{ }^{\circ} \mathrm{C}$, which increased with PEKK content [7]. Gaymans developed triblock and multiblock semi-crystalline PAESs with monodisperse amide segments by both solution and the melt methods [8]. As a result, crystallinity was introduced with $\mathrm{T}_{\mathrm{m}} \mathrm{S}$ ranging from $220{ }^{\circ} \mathrm{C}$ to $270{ }^{\circ} \mathrm{C}$. The $\mathrm{T}_{\mathrm{m}} \mathrm{S}$ increased linearly with amide segment content. The crystallization windows of 
semicrystalline polymers were defined by the temperature region between $T_{g}$ and $T_{m}[9]$. For these PAES copolymers, crystallization windows are relatively small to obtain fast crystallization. Recently, Long et al. synthesized multiblock copolymers containing alternating PAES and poly(butylene terephthalate) (PBT) segments [10]. Semicrystalline morphology was obtained with amorphous bisphenol-A-based PAES oligomers $\left(\mathrm{M}_{\mathrm{n}}=6000 \mathrm{~g} / \mathrm{mol}\right)$ and crystallizable PBT segments, when the composition of PAES was below $80 \mathrm{wt} \%$ in the copolymer.

Poly(1,4-cyclohexylenedimethylene terephthalate) (PCT) is well-known commercial semicrystalline polyester. Due to the rigidity of cyclohexylene ring, PCT has a higher $\mathrm{T}_{\mathrm{m}}$ than PBT $\left(222^{\circ} \mathrm{C}\right)$ and poly(ethylene terephthalate) (PET) $\left(260{ }^{\circ} \mathrm{C}\right)$ in most cases. $\mathrm{T}_{\mathrm{m}}$ of PCT is dependent on the cis/trans ratio of CHDM, ranging from $250{ }^{\circ} \mathrm{C}$ (all cis-CHDM) to $315^{\circ} \mathrm{C}$ (all trans-CHDM) [10-12]. The PCT structure has also been modified by copolymerizing with other comonomers such as isophthalic acid to adjust physical and chemical properties [12, 13]. The cyclohexylene moieties introduced by 1,4-cyclohexanedimethanol (CHDM) provide sub $T_{g}$ relaxations, that enhance the impact strength. Yee and coworkers studied the secondary relaxations of PET, PCT, and their copolymers. They found the presence of cyclohexylene rings corresponds to secondary relaxations, which were observed by dynamic mechanic analysis (DMA). They attributed the relaxations to interconversion between chair and twist-boat conformations adopted by the cyclohexane rings $[14,15]$. They also stated that the combined movements of multiple cyclohexane units result in relatively large-scale translational motions, which increase volume fluctuations and improve the impact 
properties of the materials. Our previous study of PAESs containing cyclohexylene rings also revealed the similar secondary relaxations around - 100 ${ }^{\circ} \mathrm{C}$ in DMA tan delta profiles, and these relaxations have the potential to enhance impact strength and ductility $[16,17]$. The configuration of cyclohexylene rings also affects the chain packing and crystallization behavior. The melting temperatures of PCT range from $250{ }^{\circ} \mathrm{C}$ (all cis-CHDM) to $315{ }^{\circ} \mathrm{C}$ (all transCHDM), which significantly influences the properties and applications of the material. Thus, the cis/trans ratio of CHDM is important for the polyester properties, and the cis/trans CHDM does not isomerize during the polymerization.

We have synthesized semi-crystalline PAESs by different methods. Terphenyl groups were incorporated into the backbone in both random and segmented fashion. The segmented copolymer with 50 mol\% of 4,4'-dihydroxybiphenyl (DHBP) and 50 mol\% of 4,4'-dihydroxyterphenyl (DHTP), showed a melting peak at $320{ }^{\circ} \mathrm{C}$ and a $\mathrm{T}_{\mathrm{g}}$ at $215^{\circ} \mathrm{C}$, which results in a crystallization window of $100{ }^{\circ} \mathrm{C}$ [4]. Another series of semi-crystalline PAESs were synthesized containing trans1,4-cyclohexylene rings. These polymers were synthesized from PAES oligomers and trans-1,4-cyclohexylene acid chloride monomers via pseudo-interfacial and solution methods. Crystallinity was observed for biphenyl based PAESs, but the crystallization rate was still slow $[16,17]$. In the present work, we synthesized $2000 \mathrm{~g} / \mathrm{mol}$ PAES oligomers with biphenyl (BP) as the bisphenol monomer. The phenolic end groups of these oligomers were converted to primary alcohol end groups by quantitative reaction with ethylene carbonate. The resulting hydroxyl end-capped PAES oligomers were polymerized with dimethyl terephthalate (DMT) 
and two different racemic mixtures of CHDM (all trans and cis/trans $=30 / 70$ ) to yield segmented copolymers via melt-phase polycondensation. The compositions were varied to produce a series of copolymers, with each having a different PCT segment content. The polymers were characterized to investigate the effect of the ester segments on the morphology and properties. For both all-trans and 30/70 cis/trans mixture of CHDM, crystallization was observed when ester content exceeded $50 \mathrm{wt} \%$.

\section{Experimental}

\subsection{Materials}

Dichlorodiphenyl sulfone (DCDPS, 98\%), 4,4'-biphenol (BP, 97\%), potassium carbonate $\left(\mathrm{K}_{2} \mathrm{CO}_{3}, \geq 99 \%\right)$, ethylene carbonate $(\mathrm{EC}, \quad \geq 99 \%)$, dimethyl terephthalate (DMT, $\geq 99 \%), 1,4$-cyclohexylenedimethonal $($ cis/trans $=30 / 70$, 99\%), trans-1,4-cyclohexylenedimethanol (all trans, 99\%) were purchased from Aldrich, and dried before use. Dimethylacetamide (DMAc, $\geq 99 \%$ ) was purchased from Aldrich and used with no further purification. Titanium(IV) butoxide (97\%) was purchased from Aldrich and dissolved in $n$-butanol (Aldrich, 99.8\%) with 0.02 $\mathrm{g} / \mathrm{mol}$ concentration. Toluene, dimethylformamide (DMF, 99.9\%), and trifluoroacetic acid (TFA, 99\%) were purchased from Fisher Scientific, and used as received.

\subsection{Synthesis of biphenyl based poly(arylene ether sulfone)s oligomer with phenol end groups}

As illustrated in the first step of Scheme 1, PAES oligomer synthesis was carried out with an excess of $4,4^{\prime}$-biphenol. The target molecular weight of the 
product was $2000 \mathrm{~g} / \mathrm{mol}$, and controlled based on the stoichiometry imbalance technique.

A typical procedure is shown as follows. BP $(20.48 \mathrm{~g}, 110 \mathrm{mmol})$, DCDPS (25.84 g, $90 \mathrm{mmol}), \mathrm{K}_{2} \mathrm{CO}_{3}(37.32 \mathrm{~g}, 270 \mathrm{mmol})$, DMAc $(300 \mathrm{~mL})$ and toluene $(150 \mathrm{~mL}$ ) were charged to a $1 \mathrm{~L}$ three-necked round bottom flask equipped with a mechanical stirrer, an argon inlet, and a Dean-stark trap. The reaction mixture was stirred at $140{ }^{\circ} \mathrm{C}$ under argon for $3 \mathrm{~h}$ to remove water by azeotropic distillation. The reaction temperature was then increased to $160{ }^{\circ} \mathrm{C}$ to distill toluene for $2 \mathrm{~h}$. After the polymerization proceeded at $160{ }^{\circ} \mathrm{C}$ for another $22 \mathrm{~h}$, the reaction mixture was cooled to room temperature and poured into a $5 \mathrm{wt} \%$ of $\mathrm{HCl}$ aqueous solution. A white solid was obtained by precipitation and filtration. The solid was washed with deionized water and methanol three times, respectively. The product was first air dried to remove most of methanol and water, and then dried in a vacuum oven (125 torr) at $100{ }^{\circ} \mathrm{C}$ for $18 \mathrm{~h}$. (Yield: 35.5 $\mathrm{g}, 89.3 \%)\left({ }^{1} \mathrm{H}\right.$ NMR spectrum is shown in Figure 10 in supplementary material)

\subsection{Synthesis of PAES2K with hydroxy ethoxy end groups}

The PAES2K obtained from BP and DCDPS can be further converted into hydroxy ethoxy end-capped oligomers $[18,19]$. The procedure is illustrated in the second step of Scheme 1. PAES2K $(20.00 \mathrm{~g}, 10 \mathrm{mmol})$, ethylene carbonate (2.64 g, $30 \mathrm{mmol}), \mathrm{K}_{2} \mathrm{CO}_{3}(0.42 \mathrm{~g}, 3 \mathrm{mmol})$ and DMF (150 mL) were added into a $250 \mathrm{~mL}$ three-necked round bottom flask equipped with a mechanical stirrer, an argon inlet, and a water condenser. The reaction was stirred at $100{ }^{\circ} \mathrm{C}$ under argon for $24 \mathrm{~h}$. White solid gradually precipitated from the reaction solution. After 
cooling to room temperature, the reaction mixture was poured into deionized water. A white solid precipitated and was isolated by filtration. The product was washed with deionized water three times and dried in a vacuum oven (125 torr) at $100{ }^{\circ} \mathrm{C}$ for $18 \mathrm{~h}$. (Yield: $\left.19.52 \mathrm{~g}, 93.5 \%\right)$ ( ${ }^{1} \mathrm{H}$ NMR spectrum is shown in Figure 11 in supplementary material)

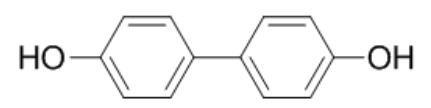

BP

Step 1

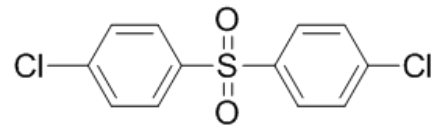

DCDPS

$\mathrm{K}_{2} \mathrm{CO}_{3}$

DMAc/Toluene

$140^{\circ} \mathrm{C}$ for $3 \mathrm{~h}, 160^{\circ} \mathrm{C}$ for $24 \mathrm{~h}$

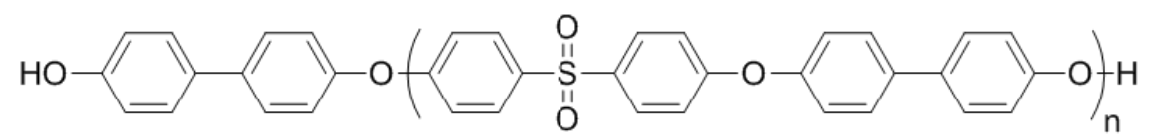

PAES2K
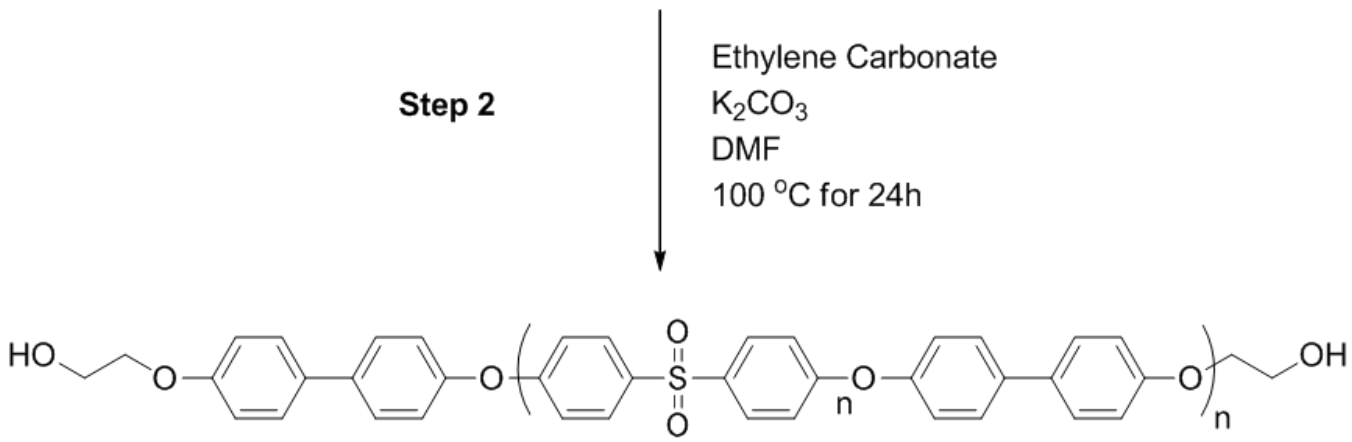

HEPAES2K

Scheme 1. Synthesis of PAES2K with hydroxyl end groups

\subsection{Melt-phase polymerization of PAES-PCT multiblock copolymers}

A series of PAES-PCT multiblock copolymers with varying compositions were synthesized in the similar manner. A typical procedure is shown below with PAES-PCT-50 as an example (Scheme 2). PAES2K (6.30 g, $3 \mathrm{mmol}$ ), DMT (4.76 
$\mathrm{g}, 24.5 \mathrm{mmol}$ ), and CHDM (cis/trans $=30 / 70,3.89 \mathrm{~g}, 27 \mathrm{mmol}$ ) were added to a $100 \mathrm{~mL}$ single-necked round bottom flask. Titanium(IV) butoxide (100 ppm) was used as the catalyst. Before the reaction was started, the flask was purged with nitrogen for $5 \mathrm{~min}$ and then evacuated $(\sim 0.2 \mathrm{mmHg})$ for $5 \mathrm{~min}$. These two steps were repeated for three cycles to remove residual moisture and oxygen in the flask. The reaction flask was lowered into a $220{ }^{\circ} \mathrm{C}$ molten metal bath and the melting reaction mixture was stirred at $200 \mathrm{rpm}$. As soon as the reaction mixture formed a clear liquid ( 5 $\mathrm{min}$ ), the reaction temperature was increased from 220 ${ }^{\circ} \mathrm{C}$ to $270{ }^{\circ} \mathrm{C}$ within $30 \mathrm{~min}$. The reaction proceeded at $270{ }^{\circ} \mathrm{C}$ under nitrogen for another $2 \mathrm{~h}$. Then the stirring rate was reduced to $30 \mathrm{rpm}$, a vacuum $(0.1-0.2$ $\mathrm{mmHg}$ ) was slowly applied, and the temperature was increased to $290{ }^{\circ} \mathrm{C}$ over $15 \mathrm{~min}$. The reaction proceeded with slow stirring (15 rpm) for another $2 \mathrm{~h}$, viscosity of the reaction mixture increased in the process. The reaction mixture was then cooled to room temperature over $15 \mathrm{~min}$ and turned opaque; crystallization was allowed in this step. The reaction flask was then lowered into the metal bath again to melt any polymer directly in contact with the inside of the flask. The stirring rod was then pulled to separate the polymer from the flask. The polymer was isolated by breaking the flask. The product was chiseled from the stirring rod and cut into small pieces. These product pieces were washed by deionized water, and then dried in vacuum oven (125 torr) at $80{ }^{\circ} \mathrm{C}$ for $18 \mathrm{~h}$. $\left({ }^{1} \mathrm{H}\right.$ NMR spectrum is shown in Figure 12 in supplementary material) 


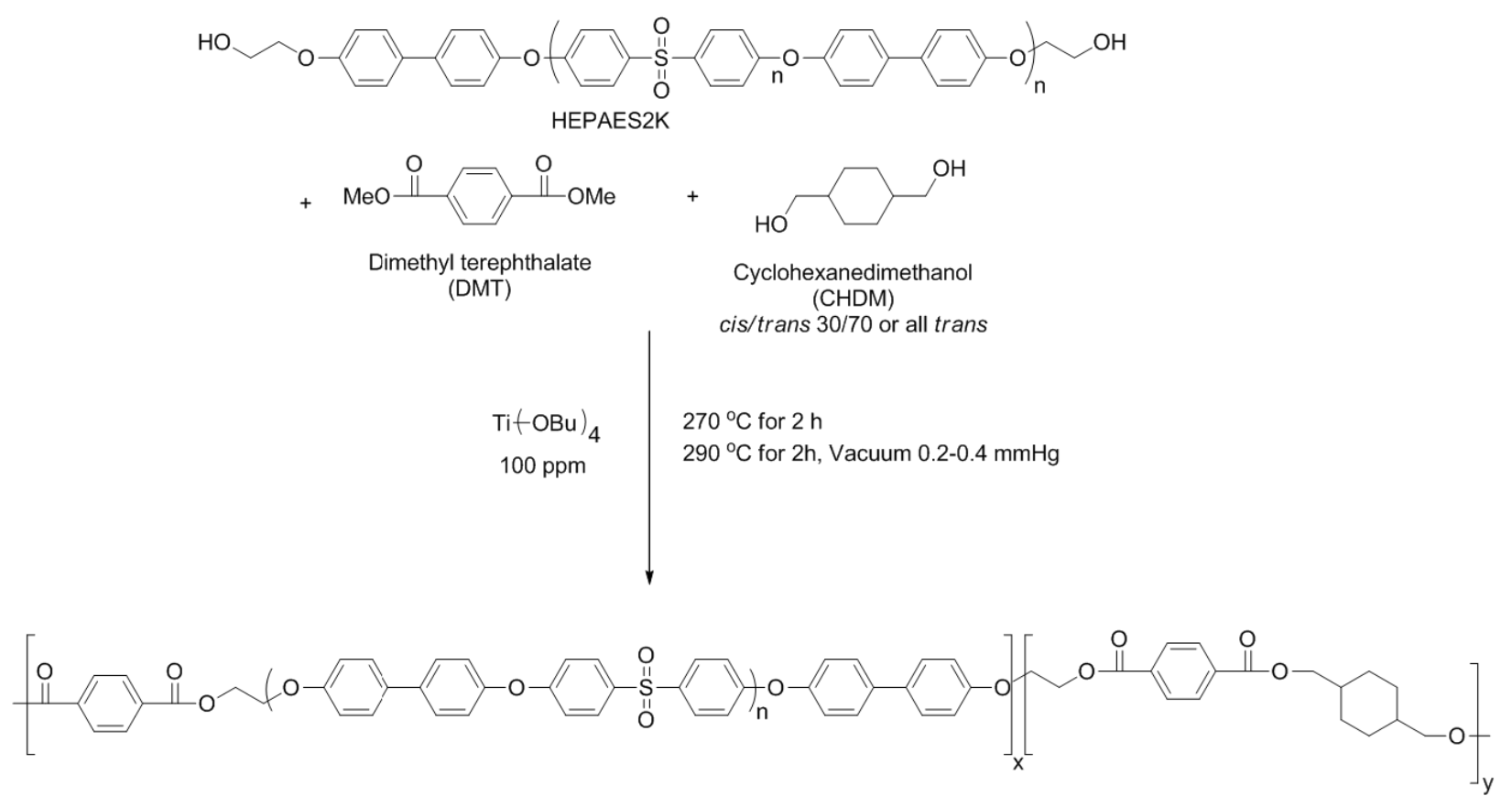

Scheme 2. Synthesis of PAES-PCT multiblock copolymers

\subsection{Preparation of polymer films}

Polymers were cut into small pieces with a chisel, and compression molded into polymer films. Before the compression molding, polymer samples were dried at $100{ }^{\circ} \mathrm{C}$ in a vacuum oven (125 torr) for $18 \mathrm{~h}$ to eliminate any residual moisture, which may cause potential degradation at elevated temperatures. Then, the samples were sandwiched between Kapton ${ }^{\circledR}$ polyimide films and compression molded at $270{ }^{\circ} \mathrm{C}$ with a pressure of $500 \mathrm{PSI}$ for $5 \mathrm{~min}$ and immediately quenched in an ice water bath. The films were dried at $60{ }^{\circ} \mathrm{C}$ in a vacuum oven (125 torr) for $18 \mathrm{~h}$, and then stored in a desiccator at room temperature.

\subsection{Instrumentation}

${ }^{1} \mathrm{H}$ NMR spectra were recorded on a Varian INOVA $500 \mathrm{MHz}$ spectrometer at room temperature using deuterated DMSO, and deuterated chloroform $\left(\mathrm{CDCl}_{3}\right)$ 
with 5 vol\% deuterated TFA as the solvents. ${ }^{1} \mathrm{H}$ NMR spectra were used to confirm the structure of PAES oligomers and PAES-PCT copolymers. Thermogravimetric analysis (TGA) was performed using a TA Instrument TGA Q500 from room temperature to $800{ }^{\circ} \mathrm{C}$ with a heating ramp of $10^{\circ} \mathrm{C} / \mathrm{min}$ under nitrogen. Differential scanning calorimetric (DSC) data were obtained on a TA Instruments Q2000 equipped with refrigerated cooling system (RCS) with a nitrogen flow of $40 \mathrm{~mL} / \mathrm{min}$. Copolymer samples were initially equilibrated at 30 ${ }^{\circ} \mathrm{C}$ for $5 \mathrm{~min}$, and then heated to $300{ }^{\circ} \mathrm{C}$ with a heating rate of $10{ }^{\circ} \mathrm{C} / \mathrm{min}$, and followed by a cooling cycle with a rate of $10{ }^{\circ} \mathrm{C} / \mathrm{min}$. The samples were equilibrated at $30^{\circ} \mathrm{C}$ for $5 \mathrm{~min}$, followed by the second heating cycle at $10{ }^{\circ} \mathrm{C} / \mathrm{min}$. Thermal transitions were determined from the second heating cycle, glass transition temperature $\left(T_{g}\right)$ was determined by the temperature of midpoint of glass transition. Dynamic mechanical analysis (DMA) was performed on a TA Instruments Q800 dynamic mechanical analyzer using the film tension mode at a frequency of $1 \mathrm{~Hz}$ and a temperature ramp of $3{ }^{\circ} \mathrm{C} / \mathrm{min}$ from -100 to $300^{\circ} \mathrm{C}$. Tensile analysis was performed on an Instron Model 4400 Universal Testing System at ambient conditions. The film samples were stamped into dog bone shaped specimens $(40 \times 4 \times 0.4 \mathrm{~mm})$ with a die according to ASTM D3368 specifications. Specimens were tested with a cross-head rate of $15 \mathrm{~mm} / \mathrm{min}$ at ambient conditions using an initial gauge length of $15 \mathrm{~mm}$. Small angle X-ray scattering (SAXS) and wide-angle X-ray diffraction (WAXS) experiments were performed using a Rigaku S-Max 30003 pinhole SAXS system, equipped with a rotating anode emitting X-ray with a wavelength of $0.154 \mathrm{~nm}(\mathrm{Cu} \mathrm{K \alpha})$. The 
sample-to-detector distance was $1603 \mathrm{~mm}$ for SAXS and $82.5 \mathrm{~mm}$ for WAXS, and the q-range was calibrated using a silver behenate standard. Twodimensional SAXS patterns were obtained using a fully integrated 2D multiwire, proportional counting, gas-filled detector, with an exposure time of $1 \mathrm{~h}$. WAXS two-dimensional diffraction patterns were obtained using an image plate with an exposure time of $1 \mathrm{~h}$. The SAXS and WAXS data were corrected for sample thickness, sample transmission and background scattering, and the WAXS profiles were vertically shifted to facilitate a comparison of peak positions. All the SAXS and WAXS data were analyzed using the SAXSGUI software package to obtain radically integrated SAXS and WAXS intensity versus the scattering vector q (SAXS) or $2 \theta$ (WAXS), where $q=(4 \pi / \lambda) \sin (\theta), \theta$ is one half of the scattering angle and $\lambda$ is the wavelength of $X$-ray.

\section{Results and Discussion}

\subsection{Synthesis of PAES oligomers and multiblock copolymers}

The PAES2K oligomers were synthesized with excess BP to control the molecular weight and end groups. Based on the Carothers equation, the feed ratio of $\mathrm{BP}$ and DCDPS was set at 11:9 to obtain PAES with number average molecular weight around $2000 \mathrm{~g} / \mathrm{mol}$. For the purpose of comparison, PAES homopolymers were synthesized in a similar fashion with a 1:1 BP:DCDPS stoichiometry.

Because the phenolic groups of PAES2K are not reactive enough for transesterification and polycondensation reactions, PAES2K was converted into HEPAES2K to obtain hydroxyethoxy end groups. Turner reported the conversion 
of phenol group to hydroxyethyl group using ethylene carbonate for a series of diphenol monomers [12], and this method was applied to oligomers and polymers $[10,19]$. Unlike the biphenol-A-based PAES, the BP-containing HEPAES2K was not soluble in chloroform or any other common organic solvents. As a result, melt-phase polymerization was chosen to copolymerize HEPAES2K with DMT and CHDM. The nomenclature of copolymer samples is based on the PAES and polyester segments and the weight percentage of polyester segment. Polyester segments from mixed CHDM (cis/trans $=30 / 70)$ are named as PCT, while tPCT refers to the polyester segments based on all trans CHDM. Therefore, PAEStPCT-20 refers to PAES-PCT multiblock copolymers with $20 \mathrm{wt} \%$ of PCT based on all trans $\mathrm{CHDM}$.

\section{$3.2{ }^{1} \mathrm{H}$ NMR analysis}

${ }^{1} \mathrm{H}$ NMR spectrum was used to analyze the structure of the oligomers and copolymers. PAES2K and HEPAES2K were characterized by ${ }^{1} \mathrm{H} N M R$, and the average number of repeat units were calculated by the ratio between the integration area of peak $f$ and peak $b$ (Figure 10). The number average molecular weight of PAES2K was $2060 \mathrm{~g} / \mathrm{mol}$ as estimated by the ${ }^{1} \mathrm{H}$ NMR results.

The completion of copolymerization was confirmed by ${ }^{1} \mathrm{H}$ NMR. As shown in Figure 11, the proton peaks of the hydroxyethoxy end groups in HEPAES2K appeared at $4.06 \mathrm{ppm}$ and $4.14 \mathrm{ppm}$, and shifted to $4.70 \mathrm{ppm}$ and $4.34 \mathrm{ppm}$, respectively, after polymerization. No obvious peaks were found around 4.06 ppm and $4.14 \mathrm{ppm}$ after polymerization, suggesting that copolymerization between the HEPAES2K oligomers and DMT was complete. The two peaks 
observed at $4.18 \mathrm{ppm}$ and $4.27 \mathrm{ppm}$ are believed to correspond to the methylene groups next to the cyclohexylene rings from CHDM. The ratio of the integration areas between these two peaks was close to the expected ratio of CHDM mixture (cis/trans $=30 / 70)$. The ${ }^{1} \mathrm{H}$ NMR spectrum of the copolymer containing tPCT segments (50 wt\%) is also shown in Figure 13. A small peak from cis-PCT was observed, but concentration of the cis isomer is expected to be fairly low (about 3 mol\%).

The weight percent of PCT segments within the copolymer was also calculated using ${ }^{1} \mathrm{H}$ NMR. As shown in Figure 12, the area of peak $\mathrm{h}$ divided by the area of peak $d$ can be used to calculate the molar ratio between PAES segments and PCT segments. As a representive example, Figure 12 exhibits the spectrum of PAES-PCT-50 (50 wt\% of PCT). The weight percentage of PCT calculated from the ${ }^{1} \mathrm{H}$ NMR spectrum was $51.6 \%$, which is in agreement with the theoretical value. The PAES-tPCT-50 (Figure 13) and other samples with different compositions also showed similar consistency.

\subsection{Thermal Stability}

The thermal stability of the copolymers was analyzed by thermogravimetric analysis (TGA). As shown in Figure 1, all the copolymers showed a two-stage thermal degradation behavior under a nitrogen atmosphere, which corresponded to the PCT and PAES segments, respectively. All the copolymers showed an initial thermal degradation temperature around $400{ }^{\circ} \mathrm{C}$. For all of the samples, as the content of PCT increased, the $T_{d}$ decreased. 


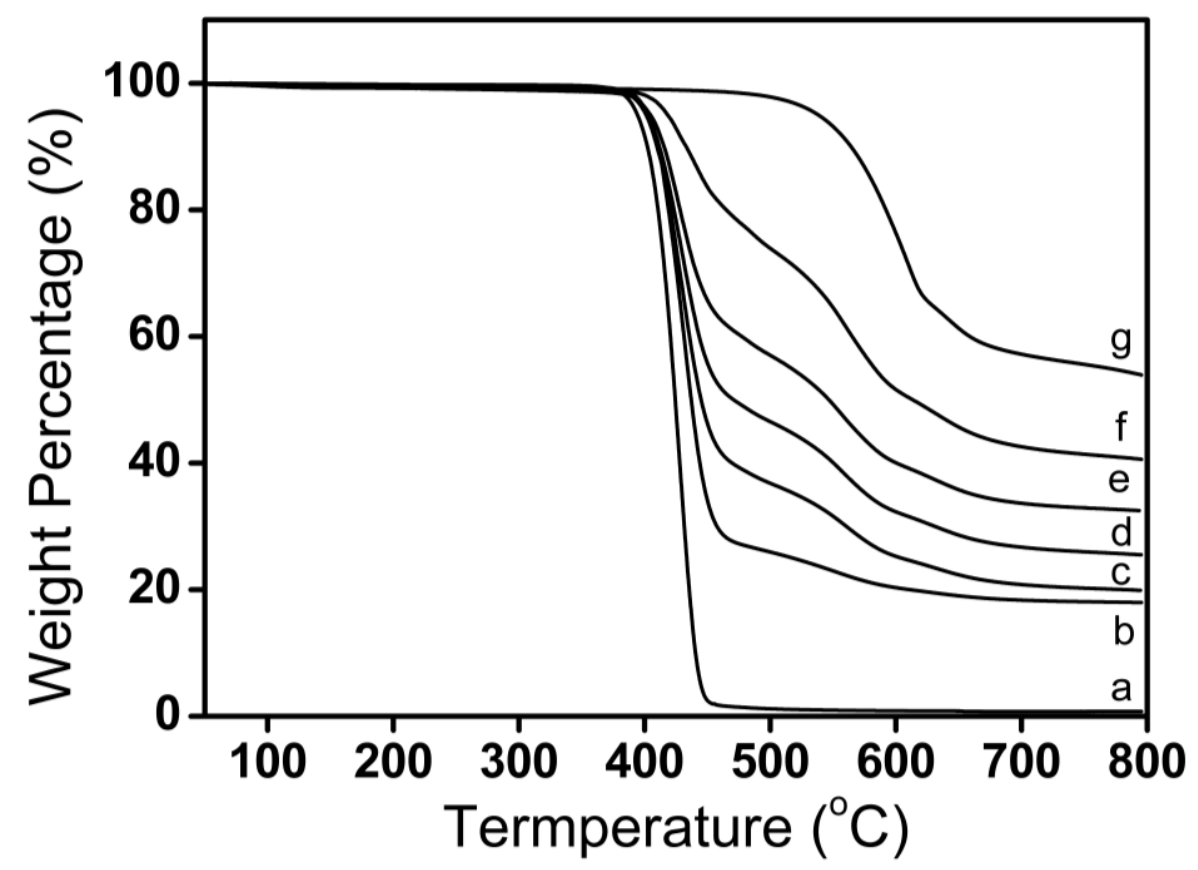

Figure 1. Thermal degradation behaviors of PAES-PCT copolymers

(a.PCT; b.PAES-PCT-80; c.PAES-PCT-60; d.PAES-tPCT-50; e.PAES-PCT-40;

f.PAES-tPCT-20; g.PAES)

\subsection{DSC analysis}

The thermal transitions of the multiblock copolymers were analyzed by DSC (Table 1). It is generally accepted that the $T_{g} s$ of copolymers correspond to the percentage of the components and their morphologies [20]. For phase-separated polymers, two glass transitions are possible; however, in this study there was only one glass transition observed for each of the samples (Figure 2 and Figure 3), which suggested phase mixing in these segmented block copolymers. It should also be noted that the $T_{g}$ decreased with increasing PCT content. For PCT and PAES homopolymers, semi-crystalline PCT has a much lower $T_{g}\left(92^{\circ} \mathrm{C}\right)$ 
compared to biphenol-based PAES $\left(224{ }^{\circ} \mathrm{C}\right)$. Thus, the copolymers with lower PCT content exhibited higher $T_{g} s$.

The crystallization behavior of the materials was investigated by measuring the $\mathrm{T}_{\mathrm{m}}$ and $\Delta \mathrm{H}_{\mathrm{m}} . \Delta \mathrm{H}_{\mathrm{m}}$ was determined by area under melting peak of DSC curves. Melting peaks were not observable when the PCT content was below $50 \mathrm{wt} \%$. However, each copolymer with more than $50 \mathrm{wt} \%$ of PCT exhibited melting peaks, and the $T_{m}$ and melting endotherm were proportional to the PCT $w t \%$. From $100 \mathrm{wt} \%$ PCT (cis/trans $=30 / 70)$ to $60 \mathrm{wt} \%$ of PCT, the melting temperatures steadily dropped from $282{ }^{\circ} \mathrm{C}$ to $262{ }^{\circ} \mathrm{C}$, and the melting endotherm decreased from $25.67 \mathrm{~J} / \mathrm{g}$ to $10.67 \mathrm{~J} / \mathrm{g}$. Higher PCT content allows easier packing of the ester segments, resulting in a greater degree of crystallization. 
Table 1. Thermal transitions of PAES-PCT and PAES-tPCT samples

\begin{tabular}{|c|c|c|c|c|c|}
\hline & $\begin{array}{c}\text { DSC }_{\mathrm{g}} \\
\left({ }^{\circ} \mathrm{C}\right)\end{array}$ & $\begin{array}{c}\mathrm{DSC}_{\mathrm{c}} \\
\left({ }^{\circ} \mathrm{C}\right)\end{array}$ & $\begin{array}{c}{ }^{D S C} T_{m} \\
\left({ }^{\circ} \mathrm{C}\right)\end{array}$ & $\begin{array}{c}\Delta \mathrm{H}_{\mathrm{m}} \\
(\mathrm{J} / \mathrm{g})^{\mathrm{a}}\end{array}$ & $\begin{array}{c}\text { DMA T }_{\mathrm{g}} \\
\left({ }^{\circ} \mathrm{C}\right)\end{array}$ \\
\hline PAES & 231 & - & - & - & 225 \\
\hline PAES-PCT-20 & 174 & - & - & - & 178 \\
\hline PAES-PCT-40 & 151 & - & - & - & 152 \\
\hline PAES-PCT-50 & 138 & - & - & - & 134 \\
\hline PAES-PCT-60 & 132 & 202 & 262 & 10.8 & 132 \\
\hline PAES-PCT-80 & 126 & - & 277 & 22.1 & 114 \\
\hline РСТ & 96 & - & 287 & 40.9 & 93 \\
\hline PAES-tPCT-20 & 175 & - & - & - & 174 \\
\hline PAES-tPCT-40 & 156 & - & - & - & 155 \\
\hline PAES-tPCT-50 & 140 & 232 & 281 & 8.6 & 144 \\
\hline PAES-tPCT-60 & 150 & - & 292 & 21.1 & 134 \\
\hline${ }^{*} \mathrm{tPCT}^{\mathrm{b}}$ & - & - & 315 & - & - \\
\hline
\end{tabular}




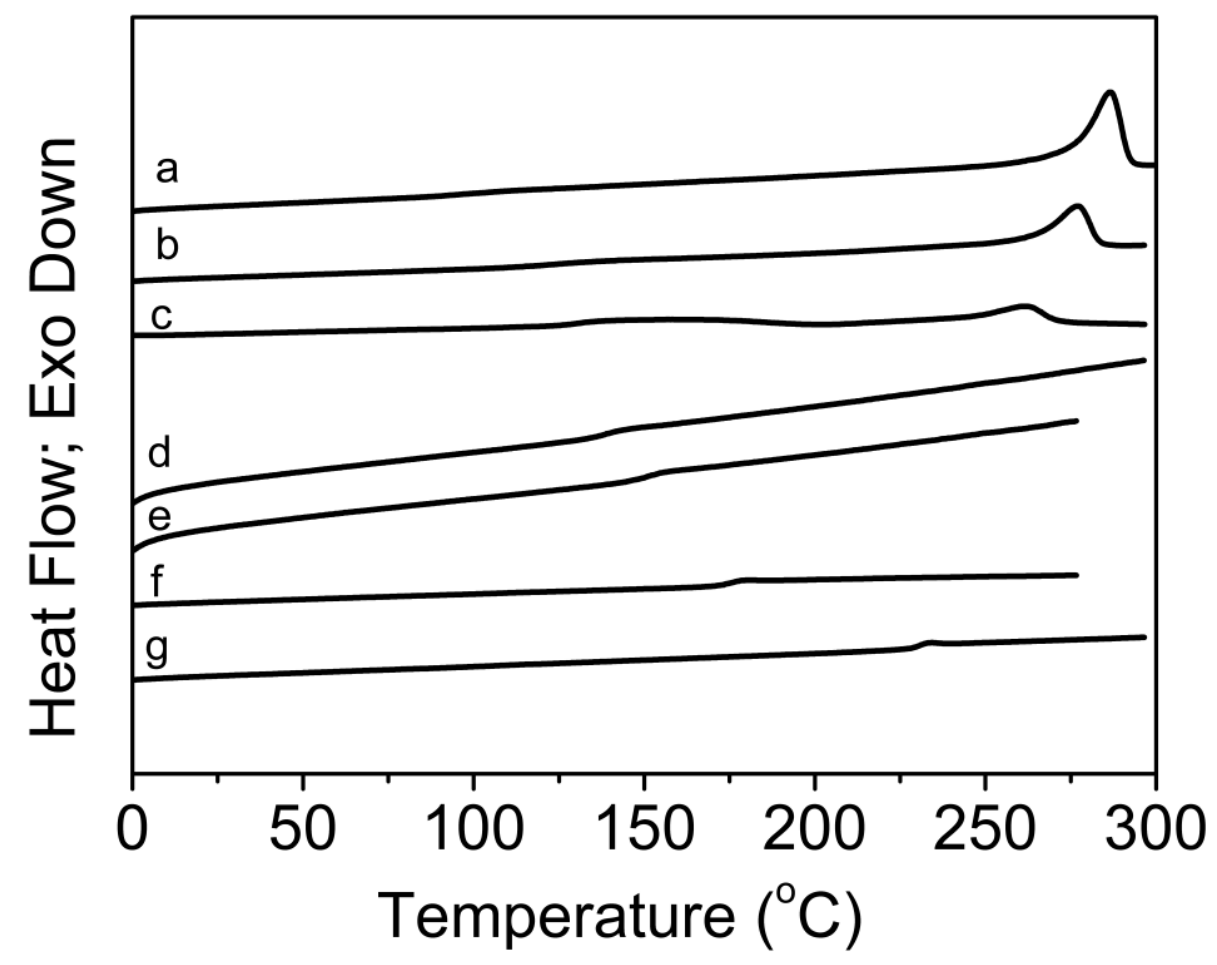

Figure 2. Thermal transitions of PAES-PCT copolymers

(a.PCT; b.PAES-PCT-80; c.PAES-PCT-60; d.PAES-PCT-50; e.PAES-PCT-40;

f.PAES-PCT-20; g.PAES)

The thermal transitions of PAES-tPCT copolymers prepared from all-trans CHDM were also studied by DSC. As evidenced in Figure 3, better regularity along the polymer backbone as a result of utilizing all-trans CHDM leads to a higher crystallinity relative to PAES-PCT analogs. This is demonstrated by the higher melting temperatures and melting endotherms. For example, the melting endotherm of PAES-tPCT-60 $(21.1 \mathrm{~J} / \mathrm{g})$ is almost double the endotherm value of PAES-PCT-60 analog $(10.8 \mathrm{~J} / \mathrm{g})$. In addition, the crystallization and melting behavior were detected for PAES-tPCT-50, while there was no sign of crystallization or melting for PAES-PCT-50. 


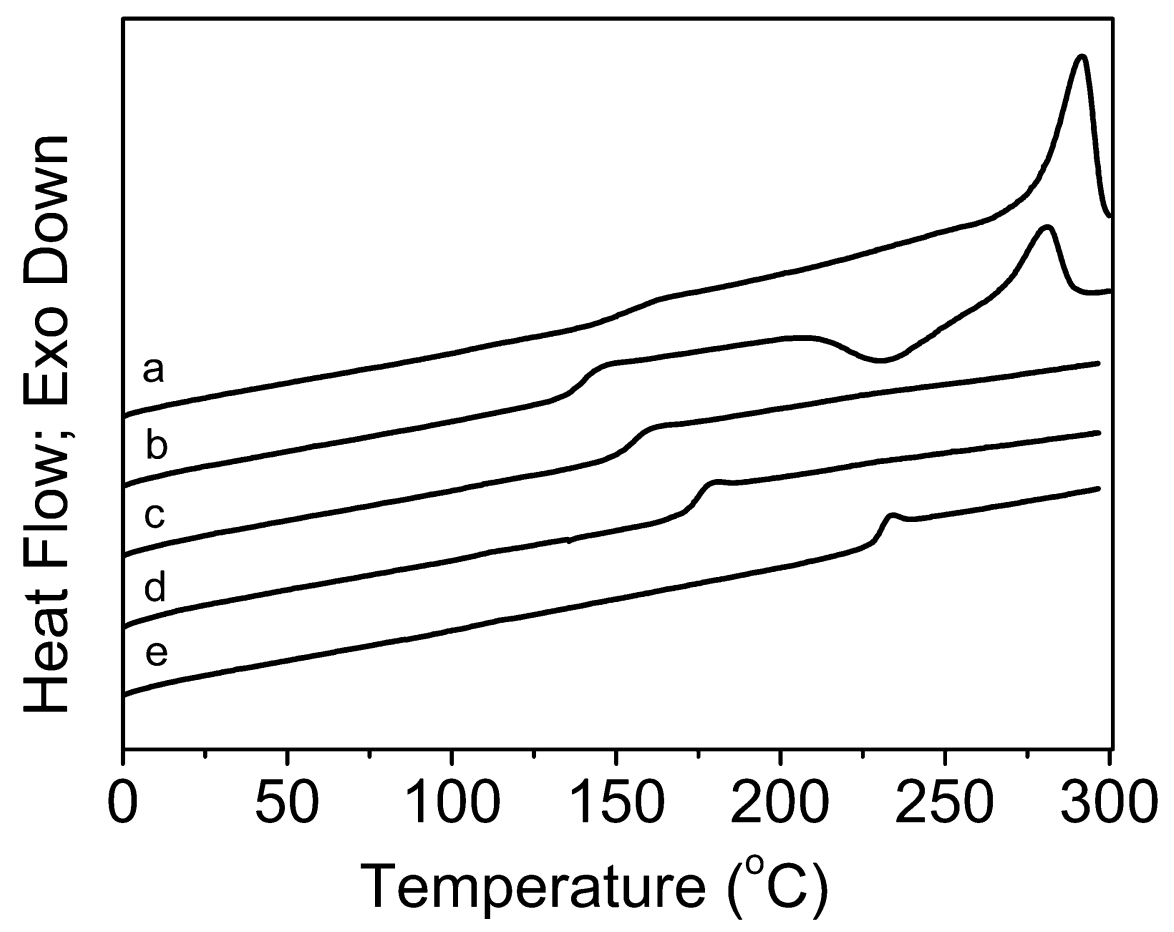

Figure 3. Thermal transitions of PAES-tPCT copolymers

(a.PAES-tPCT-60; b.PAES-tPCT-50; c.PAES-tPCT-40; d.PAES-tPCT-20;

\section{e.PAES )}

In our study, semicrystalline PAESs containing PCT or tPCT segments exhibited high glass transition temperatures, melting temperatures and wider crystallization windows (Table 1). Furthermore, biphenol-based PAES possesses a greater solvent resistance, when compared to the PAES prepared from bisphenol-A. Previous work in our group also demonstrated that the cyclohexylene ring introduced into the PCT segments provides sub- $T_{g}$ relaxation, which is potentially useful for the enhancement of impact strength of the materials [16]. 


\subsection{Thermomechanical analysis}

DMA was utilized to characterize the thermodynamic properties of the PAESPCT multiblock copolymers. As shown in Figure 4, the glass transition systematically increases from $93{ }^{\circ} \mathrm{C}$ to $225{ }^{\circ} \mathrm{C}$ as the PCT segment content decreases from $100 \mathrm{wt} \%$ to $0 \mathrm{wt} \%$. The $\mathrm{T}_{\mathrm{g}} \mathrm{s}$ measured by DMA were consistent with the values measured by DSC (Table 1).

Crystallization behavior was studied by DMA using initially amorphous samples. In order to obtain amorphous specimens for analysis, samples were prepared as follows. DMA specimens were compression molded at temperatures $10{ }^{\circ} \mathrm{C}$ higher than their $\mathrm{T}_{\mathrm{m}}$ (if they were semi-crystaline) or at $250{ }^{\circ} \mathrm{C}$ if they were amorphous. All films were immediately quenched in an ice bath to give each sample a similar thermal history. This method minimized crystallization and preserved the crystallizable PCT segments in an amorphous state before analysis. The samples were not thermally annealed before the DMA experiments. As a result, crystallization of the PCT segments can be observed around $T_{c}$, as indicated by a rapid increase in the storage modulus. Unlike pure PAES, the copolymers containing PCT crystalline segments displayed a temperature independent plateau following the crystallization. The storage modulus and temperature range of this plateau were directly related to the crystallizable PCT segment content. The PCT homopolymer exhibited the widest plateau, ranging from $130{ }^{\circ} \mathrm{C}$ to $260{ }^{\circ} \mathrm{C}$, and the highest storage modulus ( 100 MPa). Both the plateau width and the storage modulus decreased when the PCT content decreased to $50 \mathrm{wt} \%$. Interestingly, the PAES-PCT-50 also showed a hump 
between $200{ }^{\circ} \mathrm{C}$ to $250{ }^{\circ} \mathrm{C}$. This appears to be crystallization that was not detected by DSC, suggesting the copolymer with $50 \mathrm{wt} \%$ of PCT has the ability to crystallize under certain conditions. There was no sign of crystallization in the PAES-PCT-20 and PAES-PCT-40 samples. In these cases, the storage modulus of the PAES-PCT samples appears to be dominated by the PAES portion of the copolymers.

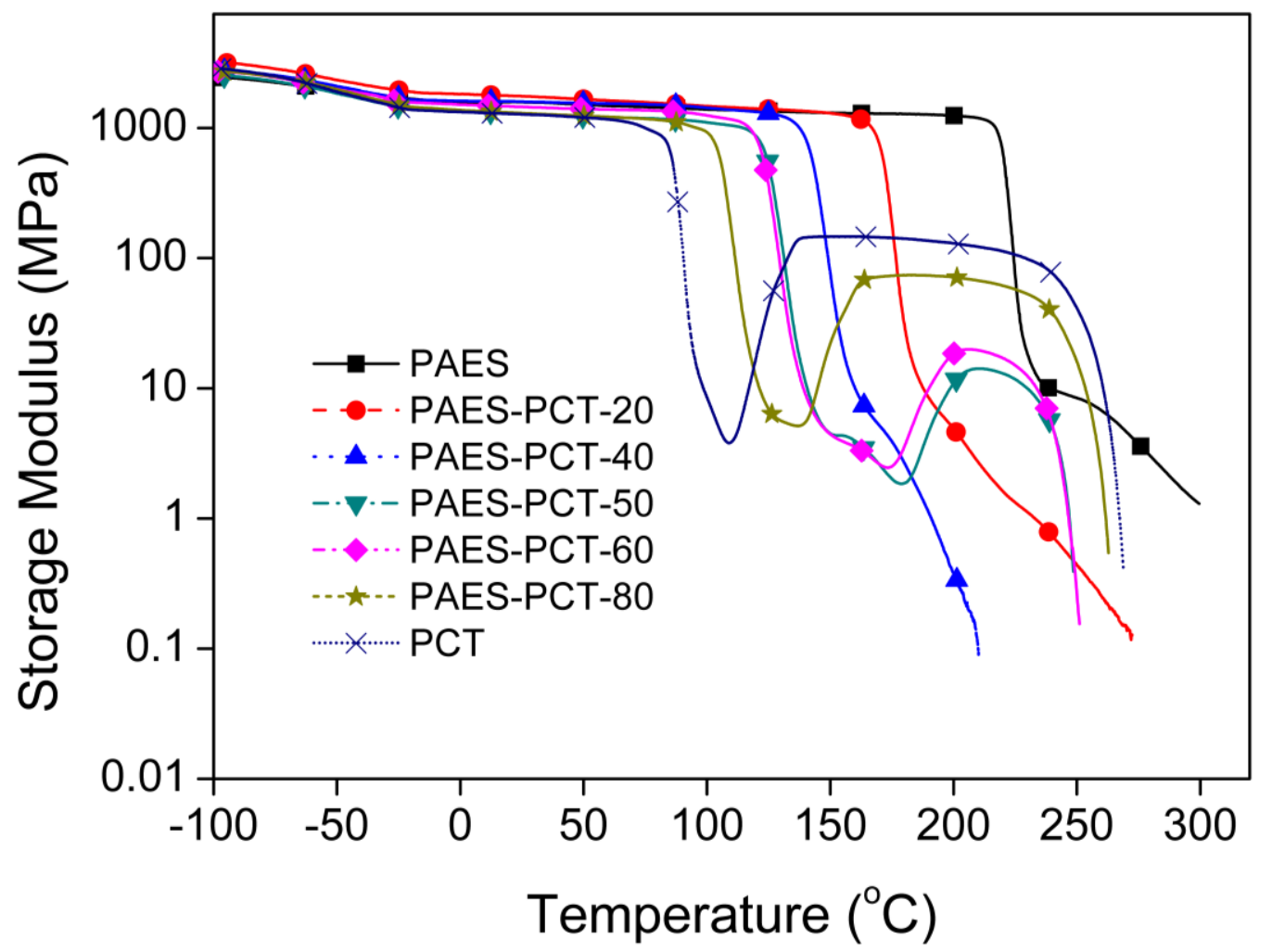

Figure 4. DMA profiles of PAES-PCT copolymers

The PAES-tPCT multiblock copolymers were also analyzed using DMA. The $T_{g} s$ of the materials increased with decreasing tPCT content (Figure 5). PAEStPCT samples containing more than $40 \mathrm{wt} \%$ of tPCT showed an increased storage modulus, which we attribute to the crystallization of tPCT segments. 
Similar crystallization behavior was observed in the PAES-PCT samples. This result further confirms that more than $40 \mathrm{wt} \%$ of ester segments are required to obtain crystallinity for both PCT and IPCT.

However, when compared to samples with 30/70 cis/trans PCT, PAES-tPCT samples showed a greater tendency toward crystallization. This is made evident by the width and storage modulus of the plateau after crystallization. For example, the PAES-tPCT-50 exhibited a plateau with a similar width and storage modulus as PAES-PCT-50, but the plateau of PAES-tPCT-60 continued from $180{ }^{\circ} \mathrm{C}$ to $240{ }^{\circ} \mathrm{C}$ with a higher storage modulus, around $30 \mathrm{MPa}$, when compared to the PCT analog.

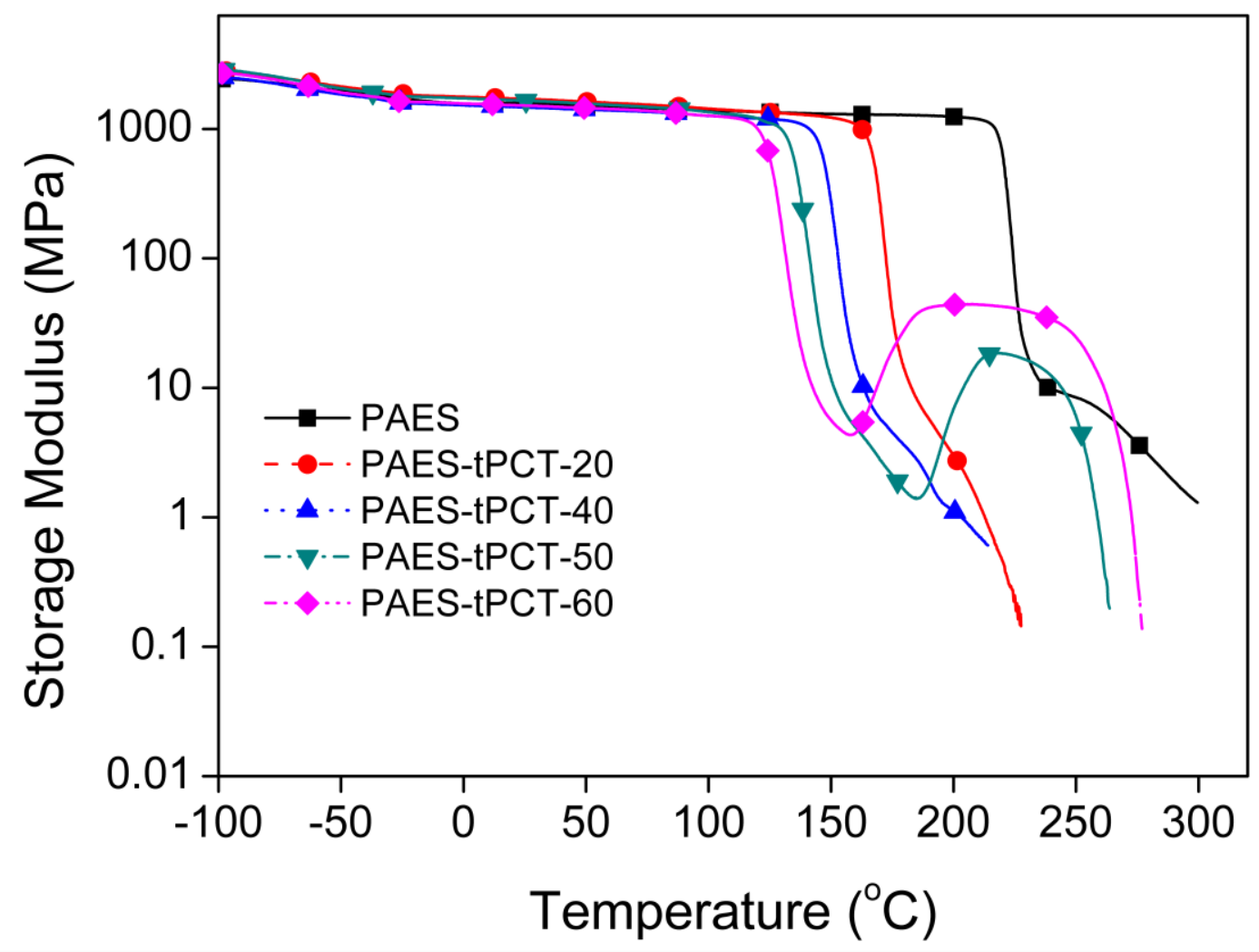

Figure 5. DMA profiles of PAES-tPCT copolymers 


\subsection{Characterization of PCT/tPCT crystalline components}

WAXS was used to characterize the crystallization and microphase separation of the copolymers. Before the analyses, the samples were annealed at $200{ }^{\circ} \mathrm{C}$ for $24 \mathrm{~h}$ to promote crystallization.

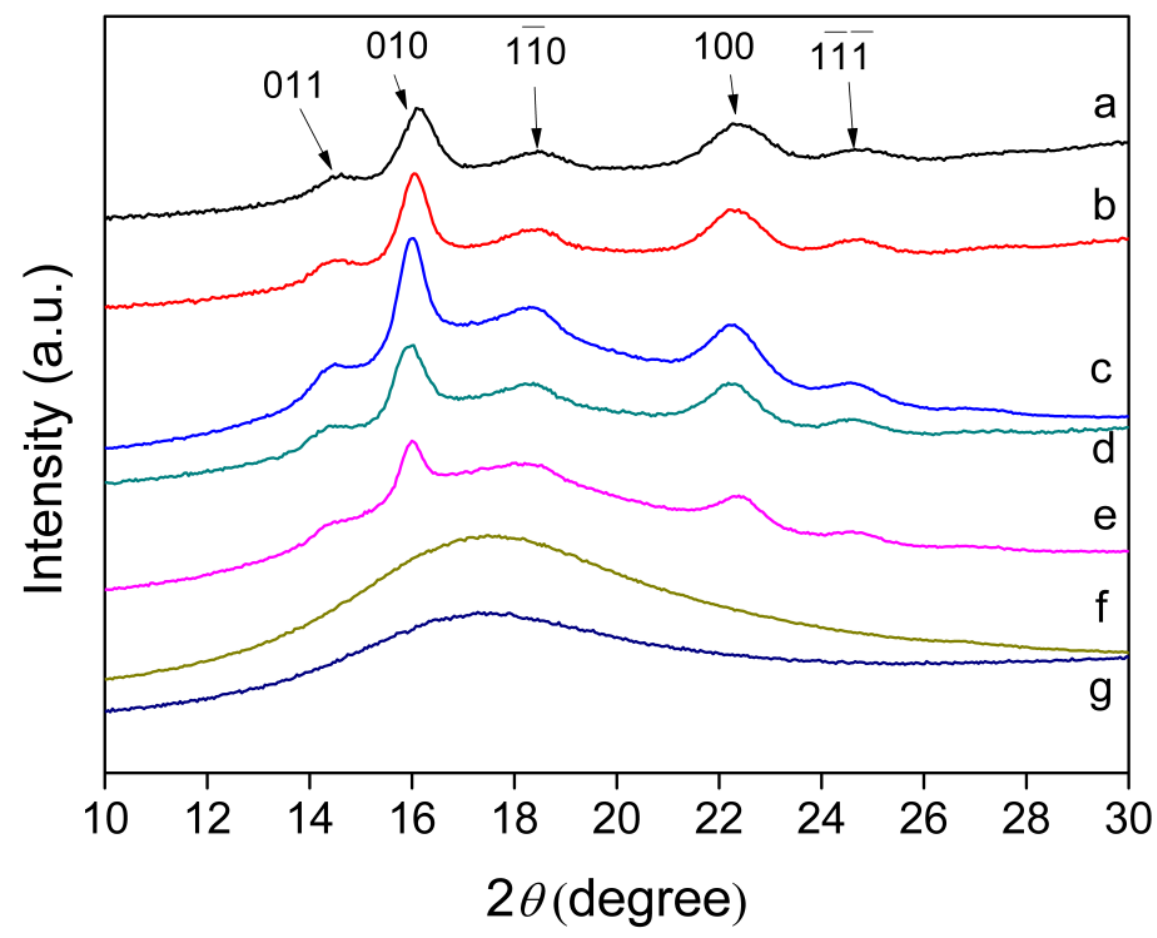

Figure 6. WAXS profiles of annealed PAES-PCT copolymers (a.PCT; b.PAES-PCT-80; c.PAES-PCT-60; d.PAES-PCT-50; e.PAES-PCT-40; f.PAES-PCT-20; g.PAES) 


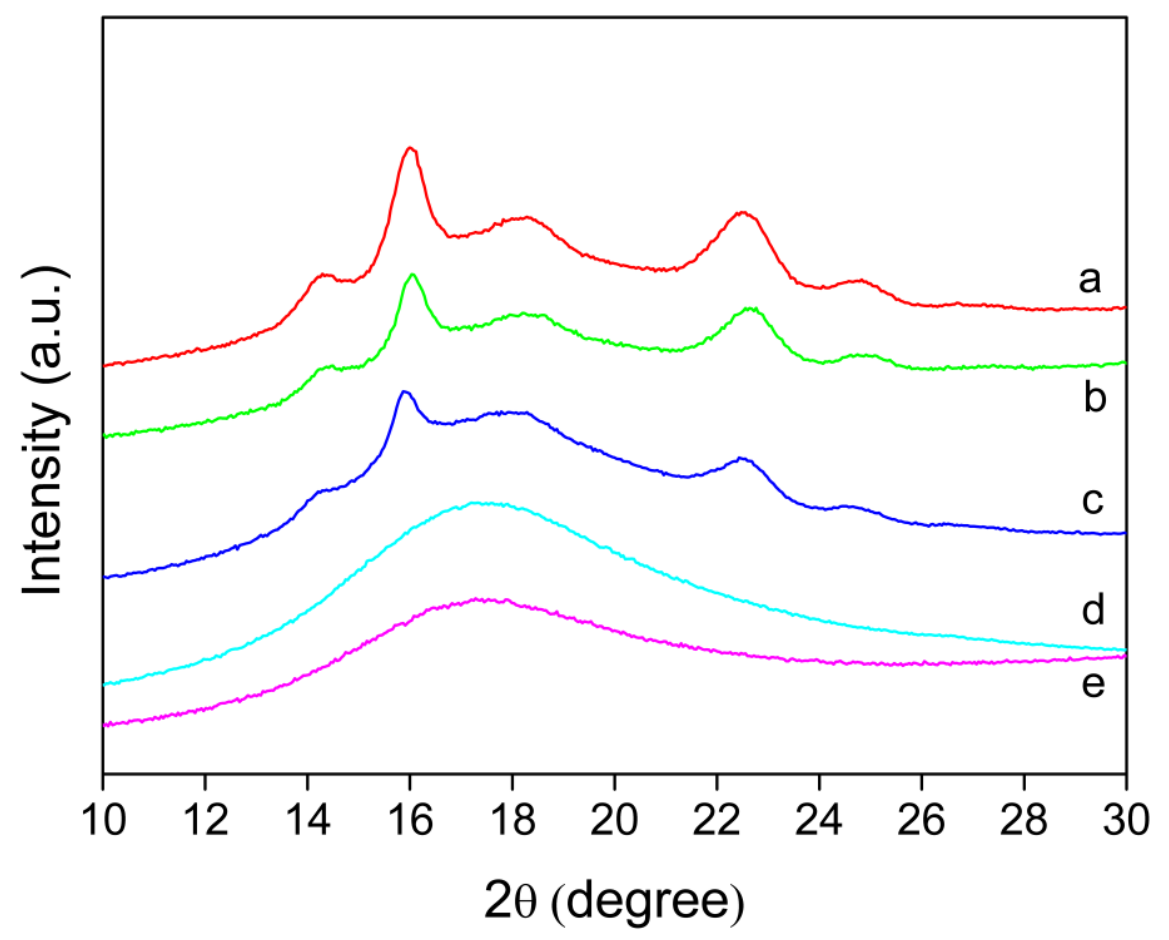

Figure 7. WAXS profiles of annealed PAES-tPCT copolymers

(a. PAES-tPCT-60; b.PAES-tPCT-50; c.PAES-tPCT-40;

d.PAES-tPCT-20; e.PAES )

As shown in Figure 6, reflection peaks appear at $14.5^{\circ}, 16.1^{\circ}, 18.5^{\circ}, 22.3^{\circ}$, and $24.8^{\circ}$ for the samples with $40 \mathrm{wt} \%$ or higher PCT components. These peaks are attributed to the crystallized PCT segments in the copolymers. It is reported that IPCT has a triclinic crystal structure, with the unit cell dimension as $a=0.646$ $\mathrm{nm}, b=0.665 \mathrm{~nm}, c=1.422 \mathrm{~nm}, \alpha=89.45^{\circ}, \beta=47.03^{\circ}$, and $y=114.95^{\circ}[21,22]$. The peaks at $14.5^{\circ}, 16.1^{\circ}, 18.5^{\circ}, 22.3^{\circ}$, and $24.8^{\circ}$ correspond to $011,010,1 \overline{1} 0$, 100, and $1 \overline{1} \overline{1}$ planes of triclinic crystal structure [21]. As expected, the relative intensities of the crystalline reflections decrease with increasing PAES content. 
Only a broad amorphous peak was observed for the copolymers with less than $40 \mathrm{wt} \%$ of PCT, and the intensity of this broad peak decreased as the PCT content increased, which corresponded to an increasing crystallinity in agreement with the thermal studies. The PAES-tPCT copolymers showed a similar trend as the PAES-PCT series. Crystallization peaks were observed when PCT content was $40 w t \%$ or higher, and the positions of peaks were essentially identical to the peak positions of PAES-PCT samples (Figure 7), which is similar to results reported in the previous work [21, 22]. 


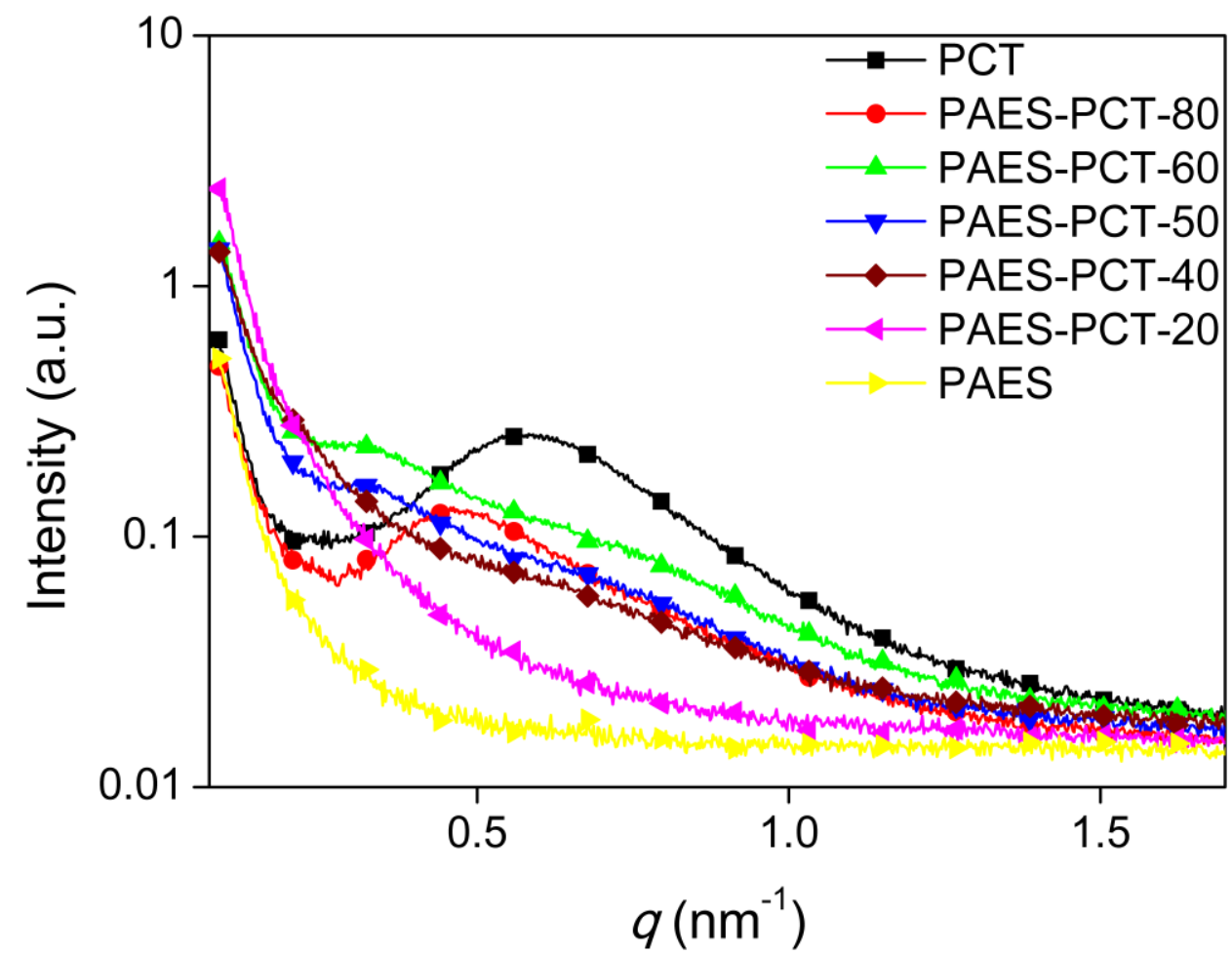

Figure 8. SAXS profiles of PAES-PCT copolymers

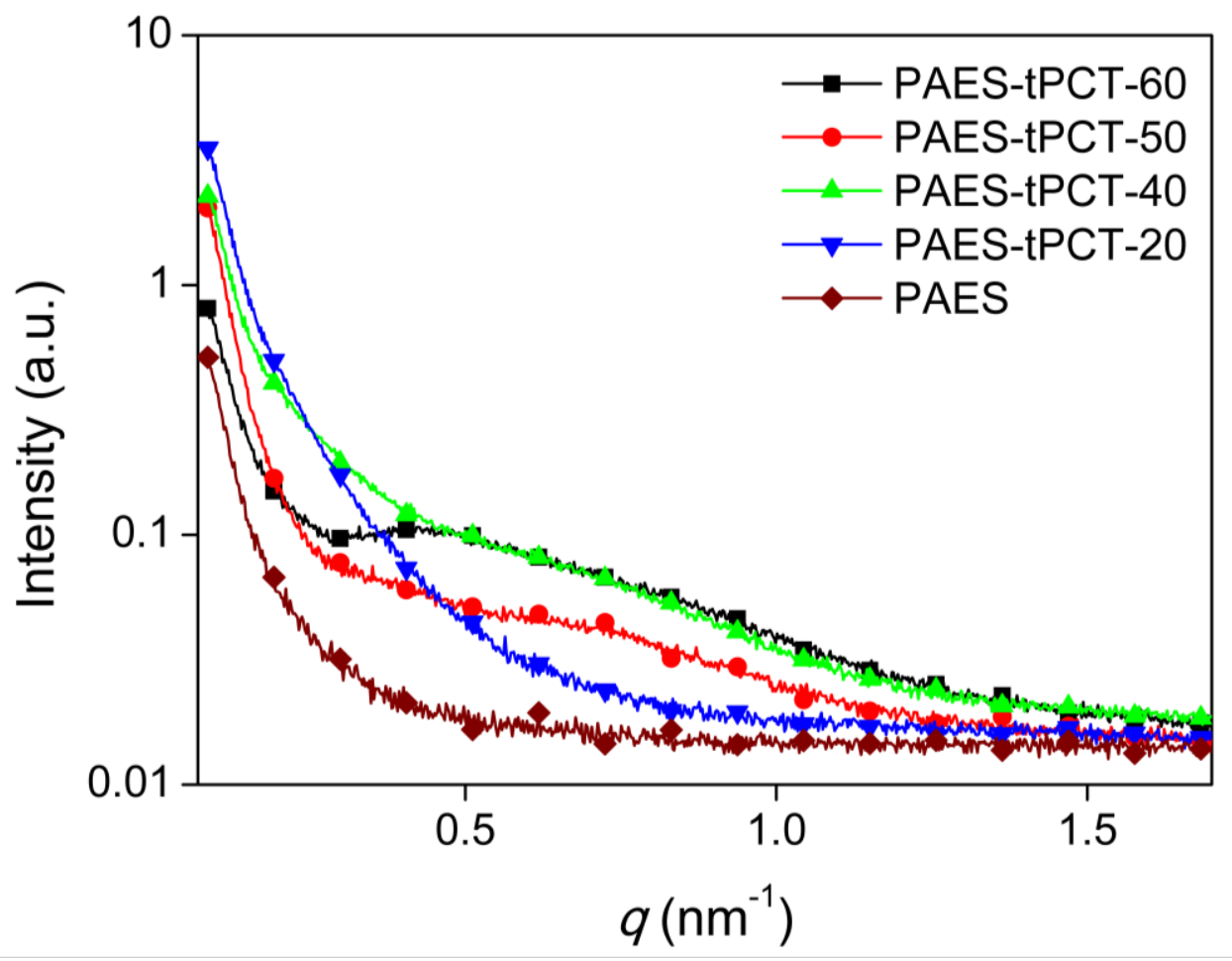

Figure 9. SAXS profiles of PAES-tPCT copolymers 
SAXS was used to investigate the long range periodicity of the lamellar structure of these samples. As shown in Figure 8, all the samples except PAES homopolymer and PAES-PCT-20 exhibited a scattering peak in the range of $q=$ 0.4 to $0.6 \mathrm{~nm}^{-1}$, corresponding to lamellar spacing of 10.5 to $15.7 \mathrm{~nm}$. Moreover, as PCT composition decreased, scattering peak of these samples shifted to lower $q$ values, which suggested a trend of increasing interlamellar dimension (i.e. greater amorphous content between lamellae). Although copolymers with tPCT segments have higher crystallinity than their cis/trans PCT-based analogues, no significant increase in the scattering behavior was observed in these SAXS measurements (Figure 9). Previous work suggested the high level of microphase separation of polysulfone-polyester copolymers was obtained by using higher molecular weight polyester segments $(\sim 6000 \mathrm{~g} / \mathrm{mol})[10]$.

\section{Conclusion}

DMT and CHDM were copolymerized with amorphous biphenyl based PAES oligomers $\left(M_{n}=2000 \mathrm{~g} / \mathrm{mol}\right.$ with primary alcohol end groups) to obtain segmented polysulfone-polyester block copolymers that exhibited semicrystalline characteristics at high PCT concentration ranges. For both PCT and PCT, the composition of polyester segment needs to be above $50 \%$ to obtain observable crystallinity, studied by DSC, DMA and WAXS. The crystallinity of copolymers increases as the wt\% of PCT or tPCT increases. Comparison of copolymer crystallization behavior was also made between two polyester segments. PCT prepared from all trans CHDM exhibited a greater degree of crystallization compared to the cis/trans $30 / 70$ mixture. 


\section{Acknowledgement}

This research was partially sponsored by BASF. The authors would like to thank Professor Timothy Long`s group at Virginia Tech for assistance with TGA, DSC. The authors also thank Professor Garth Wilkes and Dr. Haoyu Liu for helpful discussion. This material is partially based upon work supported by the National Science Foundation under Grant No. DMR-0923107 and NSF-MRI Award No. 1126534. 


\section{References}

1. Gotham KV and Turner S. Polymer 1974;15(10):665-670.

2. Rao VL. J of Macromol Sci, Part C 1999;39(4):655-711.

3. Rogers ME and Long TE. Synthetic methods in step-growth polymers. Hoboken, N.J.: Wiley-Interscience, 2003.

4. Mao M, Das S, and Turner SR. Polymer 2007;48(21):6241-6245.

5. Shukla D, Negi YS, Uppadhyaya JS, and Kumar V. Polym Rev 2012;52(2):189-228.

6. Dizman C, Tasdelen MA, and Yagci Y. Polym Int 2013;62(7):991-1007.

7. Botkin JH, Cotter RJ, Matzner M, and Kwiatkowski GT. Macromolecules 1993;26(9):2372-2376.

8. Stephen R, Gibon CM, Weber M, and Gaymans RJ. J Polym Sci, Part A: Polym Chem 2010;48(1):63-73.

9. Bouma K, Regelink M, and Gaymans RJ. J Appl Polym Sci $2001 ; 80(14): 2676-2682$.

10. Dennis JM, Fahs GB, Moore RB, Turner SR, and Long TE. Macromolecules 2014;47(23):8171-8177.

11. Kibler CJ, Bell A, and Smith JG. J Polym Sci Part A 1964;2(5):2115-2125.

12. Turner SR. J Polym Sci Part A: Polym Chem 2004;42(23):5847-5852.

13. Hill AJ, Weinhold S, Stack GM, and Tant MR. Eur Polym J 1996;32(7):843-849.

14. Chen LP, Yee AF, Goetz JM, and Schaefer J. Macromolecules $1998 ; 31(16): 5371-5382$. 
15. Chen LP, Yee AF, and Moskala EJ. Macromolecules 1999;32(18):59445955.

16. Zhang B and Turner SR. J Polym Sci Part A: Polym Chem $2011 ; 49(20): 4316-4324$.

17. Zhang B and Turner SR. Polymer 2013;54(17):4493-4500.

18. Turner SR, King B, Ponasik J, Adams V, and Connell G. High Perform Polym 2005;17(3):361-376.

19. Celebi O, Lee $\mathrm{CH}$, Lin $\mathrm{Y}$, McGrath JE, and Riffle JS. Polymer $2011 ; 52(21): 4718-4726$.

20. Cureton LT and Richard Turner S. Eur Polym J 2011;47(12):2303-2310.

21. Boye CA. J Polym Sci 1961;55(161):275-284.

22. Zhang J-B, Wang X-L, He Q-X, Zhao H-B, and Wang Y-Z. Polym Degrad Stabil 2014;108(0):12-22. 


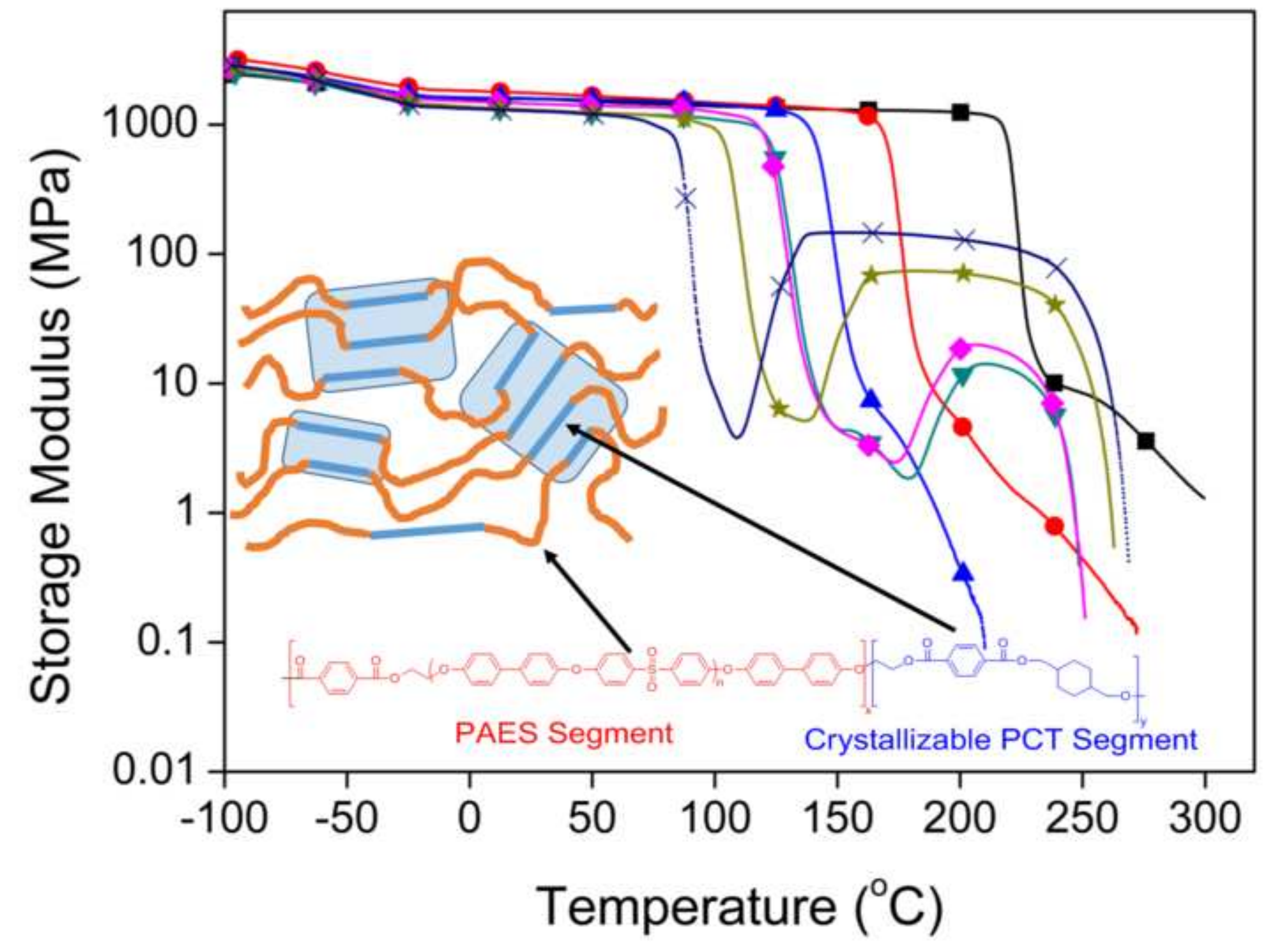

